\title{
PENGARUH VARIASI KECEPATAN PUTAR DALAM METODE STIR CASTING TERHADAP SIFAT KEKERASAN Al- SiC UNTUK APLIKASI BLOK REM KERETA API
}

\author{
Santhi Wilastari ${ }^{1)}$, AP. Bayuseno, Sri Nugroho ${ }^{2)}$ \\ 1) Jurusan Teknika, AKPELNI, Semarang \\ ${ }^{2)}$ Jurusan Teknik Mesin, Universitas Diponegoro Semarang
}

\begin{abstract}
Abstrak
Penelitian ini dilakukan untuk mengetahui tentang sifat kekerasan pada Al- SiC yang dihasilkan dari proses pengecoran dengan metode stir casting dengan variasi putaran 300, 500, dan $700 \mathrm{rpm}$ dengan lama waktu pengadukan 10 menit. Pada penelitian ini Al yang digunakan adalah $\mathrm{Al}$ hasil limbah produksi dengan penambahan $\mathrm{SiC}$ sebesar $10 \%$ sebagai penguat yang dicampurkan pada saat pengecoran. Dari hasil penelitian ditemukan bahwa nilai kekerasan hasil pengecoran dengan variasi putaran masih jauh dibandingkan kekerasan besi cor karena kadar $\mathrm{SiC}$ sebagai penguat yang dicampurkan masih sangat sedikit hanya $10 \%$ sehingga tingkat kekerasannya juga masih sangat rendah. Tetapi bila dibandingkan dengan Al murni nilai kekerasan hasil pengecoran dengan variasi putaran berada diatas Al murni yang artinya kekerasan hasil pengecoran dengan variasi putaran lebih baik daripada kekerasan Al murni. Nilai kekerasan tertinggi terjadi pada posisi bawah sedangkan nilai kekerasan terendah terjadi pada posisi atas. Hal ini terjadi karena pada saat pengecoran ada waktu jeda antara selesainya proses pengadukan dengan waktu penuangan sehingga terjadi proses pengendapan yaitu turunnya SiC ke posisi bawah.

Kata kunci: Al-SiC, Stir Casting, sifat kekerasan
\end{abstract}

\section{PENDAhULUAN}

Blok rem adalah salah satu komponen KA yang habis pakai. Umumnya material blok rem KA yang digunakan adalah besi cor kelabu. Blok rem yang materialnya menggunakan besi cor mempunyai berat $11-12 \mathrm{~kg}$, umur pemakaian hanya mencapai satu bulan. Sehingga mengakibatkan banyaknya pengeluaran untuk perawatan rutin khususnya penggantian blok rem KA yang sudah aus. Untuk mengatasi hal tersebut maka diperlukan material yang memiliki sifat keras dan ringan untuk menggantikan besi cor kelabu.

Material yang memiliki sifat keras dan ringan biasanya menggunakan material berbasis komposit antara lain: Aluminium Silicon Carbide (Al-SiC), Aluminium Oxide $\left(\mathrm{Al}_{2} \mathrm{O}_{3}\right)$, Boron Carbide $\left(\mathrm{B}_{4} \mathrm{C}\right)$, dll. Penelitian ini akan menggunakan komposit Al- SiC, dimana $\mathrm{Al}$ sebagai matrik atau material utama dan $\mathrm{SiC}$ sebagai penguatnya. Proses yang digunakan adalah proses stir casting yaitu proses pembentukan logam dengan mencairkan alumunium sampai ke titik lelehnya, lalu dicampur dengan $\mathrm{SiC}$ serbuk, selanjutnya dituang ke dalam cetakan. Penelitian ini dilakukan untuk mengetahui sifat kekersan komposit Al-SiC melalui proses stir casting dengan memvariasi kecepatan putar.

Pengaruh kecepatan putar juga diteliti oleh Aqida (2010) dengan menvariasi putaran 100, 200 dan $500 \mathrm{rpm}$ dengan variasi persentase berat 0, 5, 10 dan 15\% $\mathrm{SiC}$ dengan proses stir casting. Waktu pengadukan 15 menit pada suhu $750^{\circ} \mathrm{C}$. Pada putaran $500 \mathrm{rpm}$ terjadi porositas yang cukup banyak dimana banyak udara terjebak selama proses pengadukan. Kecepatan putaran yang rendah menyebabkan distribusi partikel tidak merata sedangkan penambahan pertikel pada matrik akan meningkatkan porositasnya. 
Baru-baru ini Bhushan dan Kumar (2011) juga meneliti tentang pengaruh sebaran partikel SiC dengan aluminium 7075 dalam KML. Dalam eksperimennya, Al $7075(0.06 \%$ berat $\mathrm{Si})$ dipadu $\mathrm{SiC}$ dengan variasi persentase berat 5, 10 dan 15\%. Metode stir casting dengan temperatur yang dijaga pada kisaran 750 sampai $800^{\circ} \mathrm{C}$ selama satu jam ini, diputar selama 10 menit masing-masing pada putaran 500, 650, dan $750 \mathrm{rpm}$ secara berturut-turut untuk sampel no. 1, 2, dan 3. Ketiga sampel ini masing-masing untuk $5 \%, 10 \%$, dan $15 \%$ berat $\mathrm{SiC}$. Ukuran spesimen adalah diameter $55 \mathrm{~mm}$ dan panjang $170 \mathrm{~mm}$. Hasil eksperimen ini menunjukkan kekuatan tarik tertinggi dicapai pada $10 \%$ berat $\mathrm{SiC}(106.30 \mathrm{MPa})$, sedangkan kekerasan tertinggi pada $15 \% \mathrm{SiC}$ yaitu sebesar 137 BHN. Peningkatan kekerasan sebesar 10.48\% ketika penguat SiC ditambahkan dari 5 sampai $15 \%$. Pada stirring dengan putaran $500 \mathrm{rpm}$, hasil metallographic memperlihatkan distribusi struktur butirannya seragam dengan batas butir terlihat sangat jelas.

\section{METODE PENELITIAN}

\subsection{Persiapan Material}

Penelitian ini menggunakan $\mathrm{Al}$ hasil daur ulang dengan pengujian komposisi dilakukan di POLMAN Ceper, Klaten seperti pada Tabel 2.1 dibawah ini dan bentuk hasil coran seperti pada Gambar 2.1.

Tabel 2.1. Komposisi Al produk daur ulang

\begin{tabular}{|lllc|}
\hline $\mathrm{Si}$ & 0,478 & $\mathrm{Ti}$ & 0,0170 \\
\hline $\mathrm{Fe}$ & 0,491 & $\mathrm{~Pb}$ & 0,0734 \\
\hline $\mathrm{Cu}$ & 0,121 & $\mathrm{Be}$ & $<0,0001$ \\
\hline $\mathrm{Mn}$ & 0,0599 & $\mathrm{Ca}$ & $<0,0558$ \\
\hline $\mathrm{Mg}$ & 0,411 & $\mathrm{Sr}$ & $<0,0005$ \\
\hline $\mathrm{Cr}$ & 0,0166 & $\mathrm{~V}$ & $<0,0100$ \\
\hline $\mathrm{Ni}$ & 0,0206 & $\mathrm{Zr}$ & 0,0173 \\
\hline $\mathrm{Sn}$ & $<0,0500$ & $\mathrm{Al}$ & 98,07 \\
\hline $\mathrm{Zn}$ & 0,115 & & \\
\hline
\end{tabular}

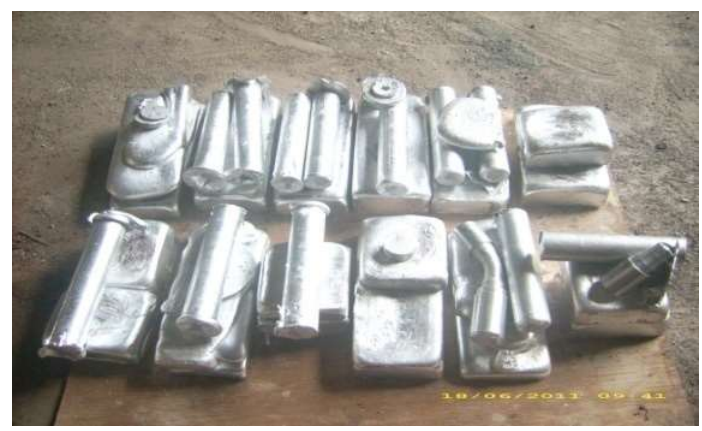

Gambar 2. 1. Al hasil coran

Sedangkan $\mathrm{SiC}$ dengan karakteristik pada Tabel 2.2 
Tabel 2.2 SiC dan karakteristiknya

\begin{tabular}{|ll|}
\hline Crystal Habit & Hexagonal/ segi enam \\
\hline Warna & $\begin{array}{l}\text { Abu-abu gelap- } \\
\text { hijau kehitaman }\end{array}$ \\
\hline Berat spesifik & $3,21 \mathrm{~g} / \mathrm{cm}^{3}$ \\
\hline Kekuatan tarik & $25.000 \mathrm{~N} / \mathrm{mm}$ \\
\hline Kinduktifitas thermal & at $293^{\circ} \mathrm{K} 41 \mathrm{~W} / \mathrm{mk}$ \\
\hline & at $873^{\circ} \mathrm{K} 335 \mathrm{~W} / \mathrm{mk}$ \\
\hline & at $1073^{\circ} \mathrm{K} 25,5 \mathrm{~W} / \mathrm{mk}$ \\
\hline Ukuran butir & $75-45 \mu \mathrm{m}$ \\
\hline
\end{tabular}

Dari bahan $\mathrm{Al}$ dan $\mathrm{SiC}$ akan dibuat sampel (specimen) dengan menggunakan metode stir casting, dengan komposisi $10 \% \mathrm{SiC}$, waktu pengadukan 10 menit, dan variasi kecepatan putaran 300, 500 dan $700 \mathrm{rpm}$. Dimensi specimen: $125 \mathrm{~mm}$, diameter $20 \mathrm{~mm}$ seperti pada Gambar 3.2. dengan pengambilan sampel untuk pengujian pada posisi atas, tengah dan bawah dengan ukuran $5 \mathrm{~mm}$

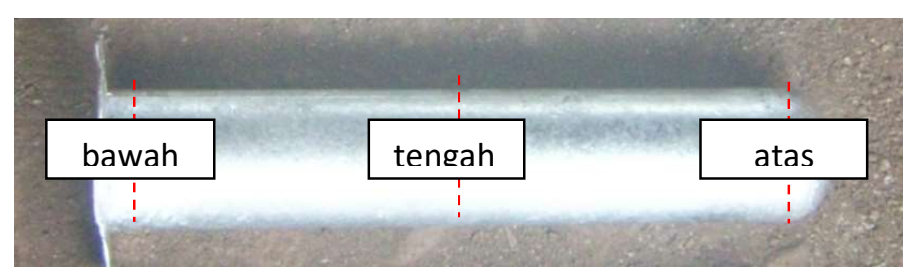

Gambar 2.2. Spesimen hasil Stir Casting

\subsection{Pengujian kekerasan}

Pengujian kekerasan dilakukan menggunakan Rockwell Hardness Tester model HR-150A dengan pengambilan sampel dilakukan 10 kali penekanan identer. Spesimen yang akan diuji dipersiapkan terlebih dahulu, dengan cara mengamplas spesimen dengan nomor amplas 1500, kondisikan rata dan tegak lurus terhadap bidang uji. Adapun langkah-langkah persiapan uji kekerasan sebagai berikut:

1. Membersihkan dan mengamplas permukaan spesimen sehingga kedua permukaan rata dan sejajar.

2. Mengkalibrasi alat uji kekerasan Rockwell hardness tester model HR-150A.

3. Memasang spesimen pada anvil dan memutar handwheel hingga spesimen tercekam cukup kuat dan jarum kecil tepat pada garis merah.

4. Memutar jarum besar pada posisi nol.

5. Melakukan pembebanan dengan memutar tuas pembebanan.

6. Memutar tuas unloading untuk menghilangkan pembebanan setelah 60 detik.

7. Mencatat skala yang ditunjukkan oleh jarum besar.

8. Mengulangi pengujian dari langkah 1 sampai dengan 7 sampai diperoleh 10 titik untuk tiap sampel. 


\section{PEMBAHASAN}

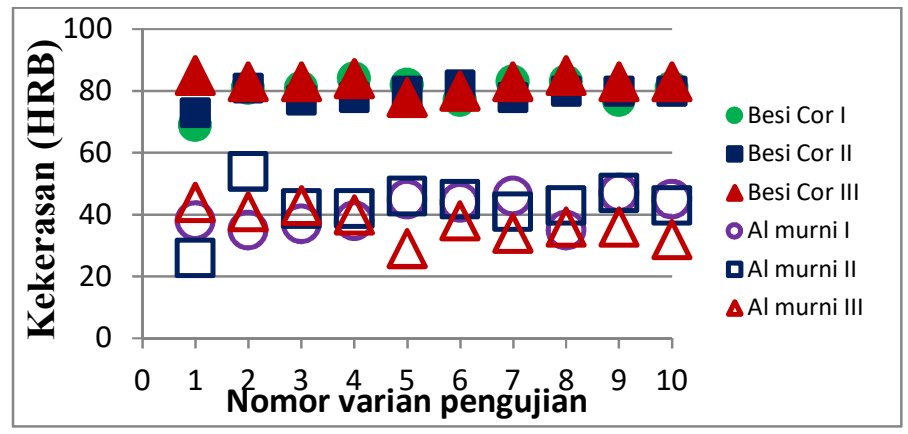

Gambar 3.1. Hasil pengujian kekersan untuk besi cor dan $\mathrm{Al}$ murni

Gambar 3.1. menerangkan tentang perbedaan kekerasan antara besi cor dengan Al murni ( belum ditambah penguat $\mathrm{SiC}$ ). Hasil pengujian pada besi cor menghasilkan kekerasan kisaran 80-80,5 HRB, sedangkan untuk Al murni kisaran 4- 4,5 HRB.

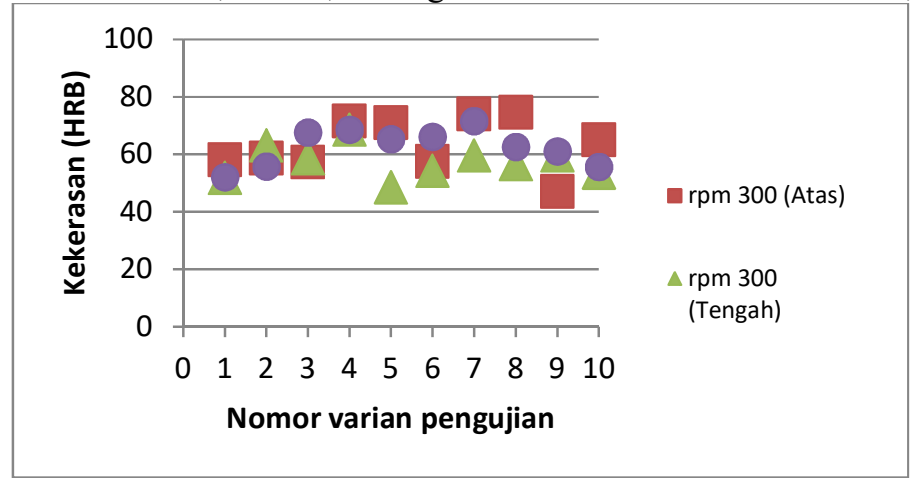

Gambar 3.2. Hasil pengujian kekerasan untuk variasi putaran $300 \mathrm{rpm}$

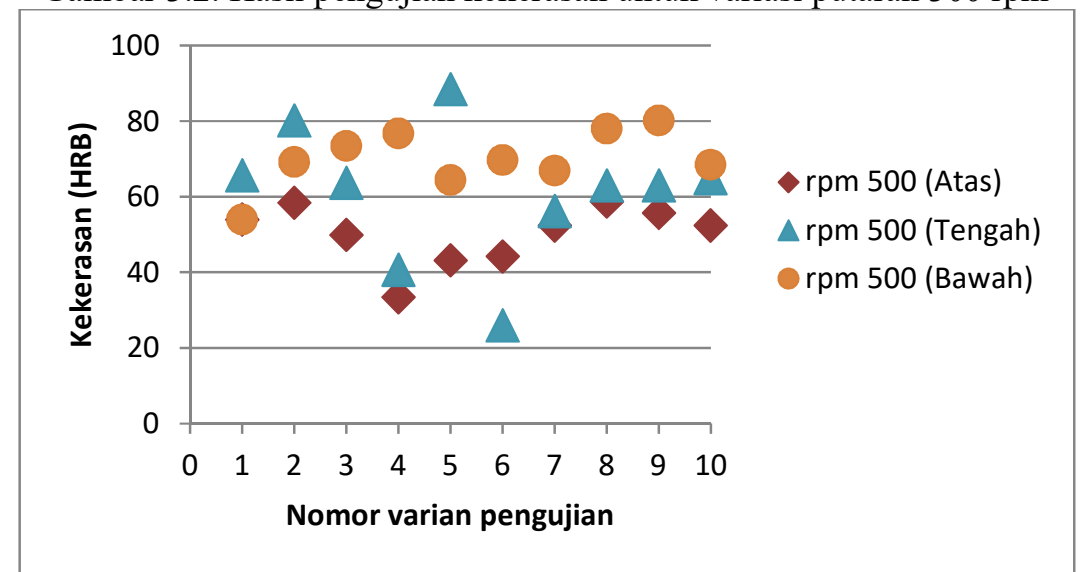

Gambar 3.3. Hasil pengujian kekerasan untuk variasi putaran $500 \mathrm{rpm}$ 


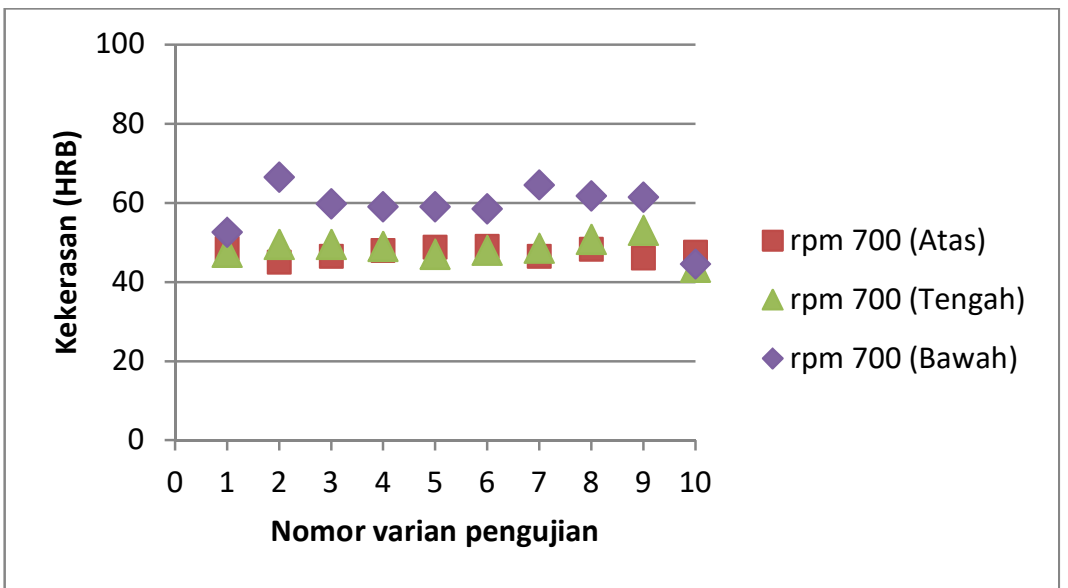

Gambar 3.4. Hasil pengujian kekerasan untuk variasi putaran $700 \mathrm{rpm}$

Sedangkan hasil pengujian untuk $\mathrm{Al}$ yang sudah dicampur dengan penambahan $\mathrm{SiC}$ sebagai penguat bisa dilihat pada Gambar 3.2; 3.3; dan 3.4. Dimana didapatkan hasil nilai rata- rata kekerasan untuk variasi putaran $300 \mathrm{rpm}$ sebesar $61 \mathrm{HRB}$, untuk variasi putaran $500 \mathrm{rpm}$ adalah 60,5 HRB dan variasi putaran $700 \mathrm{rpm}$ adalah 51,6 HRB.

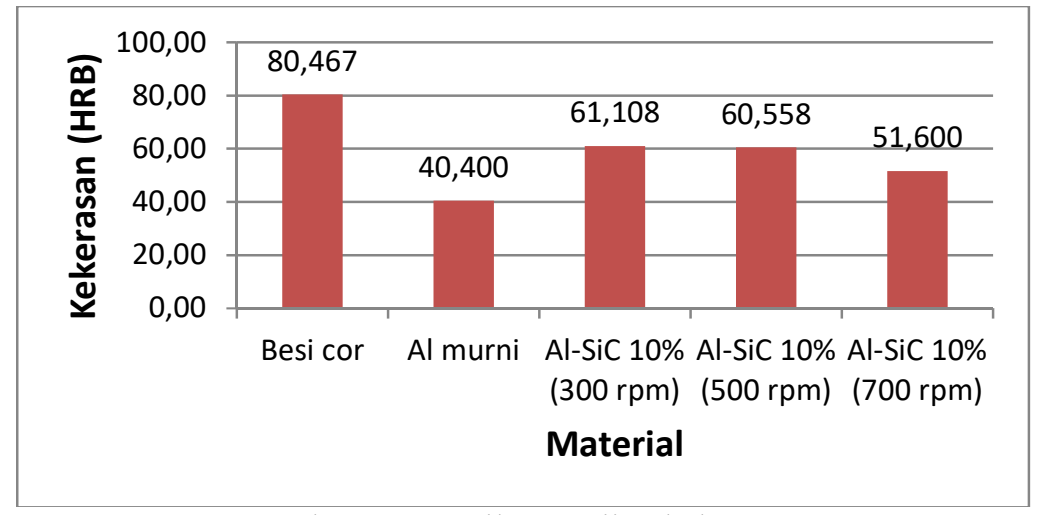

Gambar 3.5. Hasil pengujian kekerasan

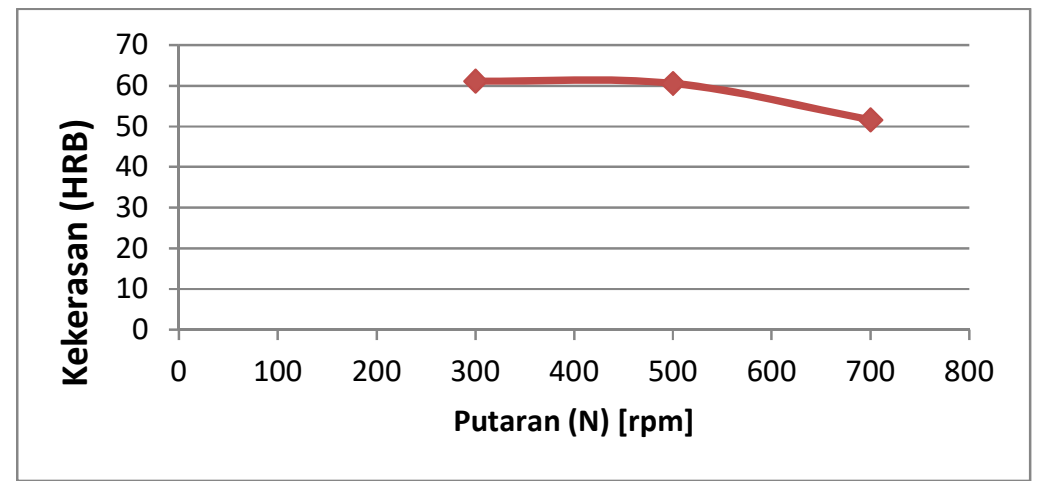

Gambar 3.6. Pengaruh putaran terhadap kekerasan

Dari Gambar 3.5. bisa dilihat bahwa nilai kekerasan hasil pengecoran dengan variasi putaran masih jauh dibandingkan kekerasan besi cor karena kadar $\mathrm{SiC}$ sebagai penguat yang dicampurkan masih sangat sedikit hanya 10\% sehingga tingkat 
kekerasannya juga masih sangat rendah. Tetapi bila dibandingkan dengan $\mathrm{Al}$ murni nilai kekerasan hasil pengecoran dengan variasi putaran berada diatas Al murni yang artinya kekerasan hasil pengecoran dengan variasi putaran lebih baik dari pada kekerasan $\mathrm{Al}$ murni.

Sedangkan pengaruh variasi putaran terhadap kekerasan yaitu semakin tinggi putaran maka nilai kekerasannya semakin berkurang, hal ini bisa dilihat pada Gambar 3.6.

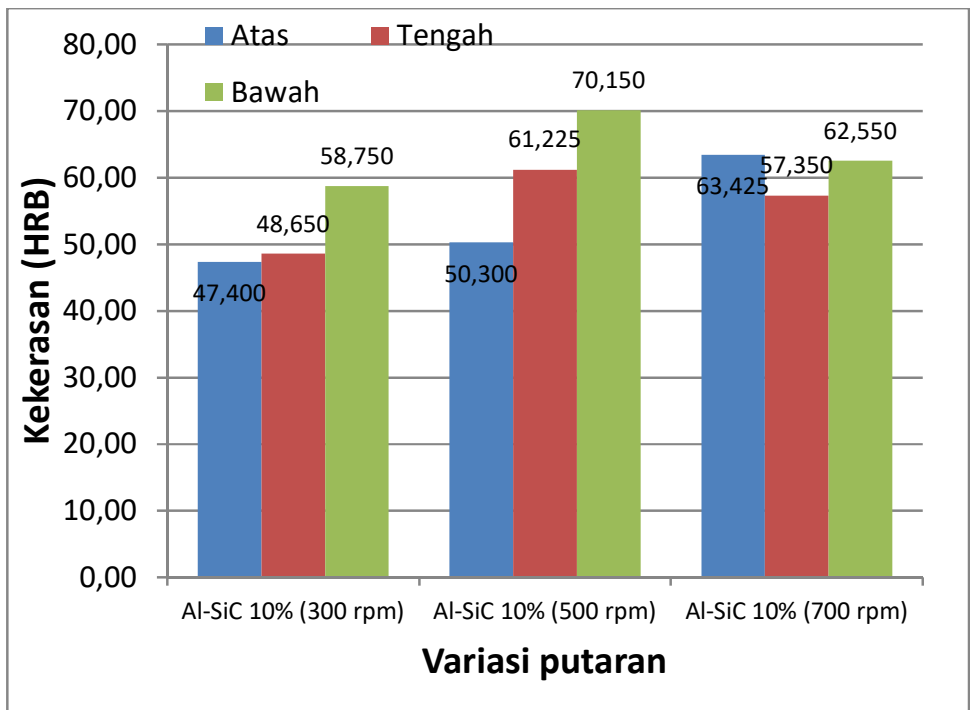

Gambar 3.7. Pengaruh letak pengujian terhadap kekerasan

Nilai kekerasan tertinggi terjadi pada posisi bawah sedangkan nilai kekerasan terendah terjadi pada posisi atas. Hal ini terjadi karena pada saat pengecoran ada waktu jeda antara selesainya proses pengadukan dengan waktu penuangan sehingga terjadi proses pengendapan yaitu turunnya $\mathrm{SiC}$ ke posisi bawah seperti terlihat pada Gambar 3.7.

\section{KESIMPULAN}

Dari penelitian ini maka dapat diambil kesimpulan:

1. Kekerasan besi cor sebagai bahan blok rem kereta api masih teteap unggul dibandingkan $\mathrm{Al}$ ataupun $\mathrm{Al}-\mathrm{SiC}$.

2. Nilai kekeresan Al- SiC mendekati nilai kakerasan besi cor, tapi perlu dilakukan penambahan Sic lebih dari 10\%, karena dalam penelitian ini hanya menambah $\mathrm{SiC}$ sebesar $10 \%$ dimana hasilnya belum cukup untuk menandingi kekerasan dari besi cor.

3. Untuk proses pengecoran stir casting perlu perbaikan supaya hasil sebaran $\mathrm{SiC}$ lebih merata pada semua posisi.

\section{DAFTAR PUSTAKA}

Aqida, SN, dkk. ( 2010), “ The Effect of Porosity on Fatigue For Cast Metal Matrix Composites". Jurnal Teknologi, 40(A), 17-32.

Aqida, SN, dkk. ( 2010), “ The Effects of Stirring Speed and Reinforcement Perticles on Porosity Formation in Cast MMC" Jurnal Mekanikal, 16, 22-30. 
Bhushan, R.K. and Kumar, S. (2011), "Influence of SiC particles distribution and their weight percentage on $7075 \mathrm{Al}$ alloy", Journal of Materials Engineering and Performance, Volume 20(2) March 2011, 317 - 323.

Bushan, RJ and Kumar, S (2009), " Optimisation of porosity of $7075 \mathrm{Al}$ alloy 10\% SiC composite produced by stir casting process through Taguchi method" , Int, J. Materials Engineering Innovation, Vol. 1. No.1

Davis, JR., dkk (1993), “Speciallty Handbook, Alumunium and Alumunium Alloys", ASM International Handbook Comitee, Ohio.

Hartomo, A. J. (1992)," Komposit Metal". Yogyakarta: Andi Offset

Kennedy, A.R., Karantzalis, A.E., and Wyatt, S.M. (1999), "The microstructure and mechanical properties of TiC and TiB2-reinforced cast metal matrix composites", J. Mater. Sci., 34, 933-940.

Miyauchi, T., dkk (2009), "Pengaruh Filter Silikon Karbida Besi Cor di Blok Rem Komposit Terhadap Kinerja Rem dan Pengembangan Proses Produksi",

Moon, H.K. (1990), "Rheological Behaviour and Microstructure of Ceramic Particulate-Aluminium Alloy Composites", PhD Thesis, MIT.

Octavianus, S, (2006), “ Studi Fase Dan Kekerasan Paduan Al-Si Setelah Penambahan Serbuk Rumah Kerang Laut Anadar Granosa Pada Proses Stir casting”, Skripsi, Universitas Kristen Petra, Surabaya

Prabu, S.B, Karunamoorthy, L., Kathiresan, S., and Mohan, B. (2006) "Influence of stirring speed and stirring time on distribution of particles in cast metal matrix composite", Journal of Materials Processing Technology, 171, 268-273.

Ray dan Kerketta (2010), " Some studies on Alumunium Matrix in -situ Composite Produced by Stir Casting Method", Master Thesis, National Institut of Technology, Rourkee

Ren, Z and Chan, S.L. (2000), "Mechanical Properties of Nanometrik Particulate Reinforced Aluminium Composites", School of Materials Science and Engineering, UNSW

Santoso, K.A. (2009), "Komposit Matriks Logam Al/SiC Pada Bahan Rem KA", Tugas Sarjana, Undip, Semarang.

Singla, M., Singh, L., and Chawla, V. (2009) "Study of wear properties of Al-SiC composites", Journal of Minerals \& Materials Characterization \& Engineering, Vol. 8, No.10, 813-819.

Susanto, L. (2004), “ Analisa Pengaruh Variasi Kecepatan Putar dan Lama Pengadukan Terhadap Sifat Mekanis Produk Stir casting”, Skripsi, Universitas Kristen Petra, Surabaya

Vincent, (2009), "Studi Pengembangan Parameter Proses Produksi Blok Rem KA Berbahan Komposit", ITB, Bandung.

www.kereta-api.co.id

Yuwono H.A., (2009), "Buku Panduan Praktikum Karakterisasi Material Pengujian Merusak (Destruktive Testing)”, Universitas Indonesia, Jakarta. 